\title{
O consumidor como agente no neoliberalismo
}

\section{The consumer as agent in neoliberalism}

\author{
- JUlio CESAR LEMES DE CASTRO* \\ Universidade Federal do Rio de Janeiro, Escola de Comunicação. Rio de Janeiro - RJ, Brasil
}

\section{RESUMO}

O discurso neoliberal, que se torna prevalente nas últimas décadas, destaca o papel ativo do consumidor. A agência do consumidor está associada a diversos fatores: retórica publicitária que enfatiza a cumplicidade com ele; tecnologias de si através das quais ele atua como empreendedor de si mesmo; mecanismos interativos que sugerem um aumento de sua participação; apelo à responsabilidade social em suas atitudes. Quando analisamos de perto cada um desses fatores, contudo, o suposto empoderamento do consumidor na contemporaneidade revela suas limitações.

Palavras-chave: Neoliberalismo, consumidor, cumplicidade, participação, empreendedorismo

\section{ABSTRACT}

The neoliberal discourse, which becomes prevalent in recent decades, highlights the active role of the consumer. The consumer agency is associated with several factors: advertising rhetoric that emphasizes the complicity with the consumer; technologies of self through which he acts as an entrepreneur of himself; interactive mechanisms which suggest an increase of his participation; appeal to social responsibility in his attitudes. When we look closely at each of these factors, however, the presumed empowerment of the consumer nowadays reveals its limitations.

Keywords: Neoliberalism, consumer, complicity, participation, entrepreneurship

* Pesquisador de pós-doutorado na Escola de Comunicação da Universidade Federal do Rio de Janeiro, com bolsa do CNPq. Graduado em Jornalismo pela Escola de Comunicações e Artes da Universidade de São Paulo (USP), com mestrado e doutorado em Comunicação e Semiótica na Pontifícia Universidade Católica de São Paulo e pós-doutorado em Psicologia Social no Instituto de Psicologia da USP. E-mail: julio@ jclcastro.com.br 


\section{A AGÊNCIA DO CONSUMIDOR NO DISCURSO NEOLIBERAL}

OS ANOS 1950 começam a proliferar as críticas à homogeneidade e
ao conformismo característicos da sociedade de massa, que do ponto
de vista econômico se apoia na articulação fordista entre produção e consumo em massa. Elas se inspiram, por exemplo, na análise de Riesman (2001) em The lonely crowd, que se torna um clássico da sociologia e um best-seller. Para esse autor, na sociedade norte-americana após a Segunda Guerra predomina a personalidade orientada para os outros, especialmente nos subúrbios, nos quais cada um se preocupa, antes de tudo, com a opinião dos vizinhos. A canção Little boxes, composta por Malvina Reynolds em 1962, alcança sucesso na voz do cantor e ativista Pete Seeger em 1963 ao ironizar a uniformidade das residências suburbanas e de seus habitantes em versos como estes (na versão em português, gravada por Nara Leão):

Uma caixa, outra caixa, todas elas iguaizinhas

Uma verde, outra rosa e uma bem amarelinha

Todas elas feitas de tic tac, todas elas iguaizinhas

[...]

As crianças vão pra escola, depois pra universidade

Onde entram em caixinhas e saem todas iguaizinhas. (Leão, 1969)

Num famoso ensaio, Mailer (1957: 278) propõe a alternativa: "Alguém ou é hip ou é quadrado [...], ou é rebelde ou conforma-se". E é nesse quadro que emerge a contracultura nos anos 1960.

O questionamento da homogeneidade e do conformismo ecoa no mundo corporativo, que se torna palco de uma série de transformações. Na esfera laboral, as propostas de empoderamento dos trabalhadores ganham influência a partir da distinção estabelecida por McGregor (1960). Para ele, a administração tradicional, taylorista, ou Teoria X, baseia-se na ideia de que as pessoas não gostam de trabalhar e necessitam de líderes que as motivem, dirijam seus esforços e controlem suas ações. Em contraposição, para a Teoria $\mathrm{Y}$ a tarefa do líder é possibilitar que os empregados reconheçam e desenvolvam a motivação, a capacidade para direcionar seu comportamento e a disposição em assumir responsabilidades que já estão potencialmente presentes em si. Nos anos 1970, segundo Boltanski e Chiapello (1999), floresce o "novo espírito do capitalismo", que incorpora a "crítica artística" à alienação do trabalho impulsionada pelos acontecimentos de maio de 1968, enfatizando a relativa autonomia do trabalhador em arranjos organizacionais baseados em rede. Essas transformações no estatuto do trabalho aprofundam-se sob a égide da ideo- 
logia neoliberal, que ganha proeminência com a chegada ao poder de Margaret Thatcher, no Reino Unido, e Ronald Reagan, nos Estados Unidos. Para o neoliberalismo, o trabalho funciona como capital humano, cujo montante depende das qualidades do trabalhador e que é remunerado na forma de salário. Isso faz do trabalhador uma espécie de empresa, e da sociedade uma coleção de unidades-empresas (Foucault, 2004: 229-231). Ao mesmo tempo, portanto, que na cultura empresarial é ressaltada a responsabilidade do trabalhador no exercício de suas funções, no âmbito social essa responsabilidade é estendida: cabe ao próprio trabalhador, investindo em si, zelar também pela reprodução de sua força de trabalho.

Em outra frente, a valorização neoliberal do mercado é acompanhada pela valorização do consumidor. É verdade que indicações da importância do consumidor já estão presentes no liberalismo clássico:

O consumo é o único fim e objetivo de toda produção, e o interesse do produtor deve ser atendido apenas na medida em que ele pode ser necessário para promover o do consumidor. Essa máxima é tão perfeitamente autoevidente que seria absurdo tentar prová-la. (Smith, 1981: 660)

No século XIX, a economia neoclássica postula a soberania do consumidor, entendido como um agente racional movido pela maximização da utilidade. Conquanto seja herdeiro da tradição que vem do liberalismo e passa pelos neoclássicos, o neoliberalismo destaca de outro modo a importância do consumidor, celebrando o poder implicado na escolha. $\mathrm{O}$ consumidor assume ostensivamente a precedência sobre o trabalhador e o cidadão como modelo hegemônico de subjetivação. Nesse contexto são fornecidos estímulos econômicos ao consumo, por meio de iniciativas como cortes de impostos, expansão do crédito e desregulamentação financeira. Mas as mudanças, no sentido de empoderamento do consumidor, que constituem o foco deste trabalho são agrupadas em quatro rubricas: retórica da cumplicidade, tecnologias de si, mecanismos de participação e responsabilidade social. Cabe assinalar que não se trata, aqui, da reapropriação posterior das mercadorias na condição de cultura material, na linha proposta por De Certeau (1990) ou Miller (1987), entre outros, mas da agência do consumidor no próprio processo de aquisição de bens.

\section{RETÓRICA DA CUMPLICIDADE}

Até os anos 1950, as estratégias retóricas utilizadas na publicidade são basicamente de três tipos. A mais tradicional é a retórica impositiva, que apela 
de forma direta e enfática ao consumidor, incitando-o a adquirir determinado produto. A mais comum é a retórica da sedução, que constrói uma fantasia em torno do produto para torná-lo atraente aos olhos do consumidor. A terceira é a retórica do convencimento, que lança mão de argumentos racionais, linguagem técnica e profissionais especializados para persuadir o consumidor. Ressalte-se que essas estratégias são tipos ideais, que podem ser combinados entre si de diversas maneiras.

Esse panorama altera-se com a chamada revolução criativa da publicidade. A campanha Think small, lançada pela Doyle Dane Bernbach (DDB) em 1959 para promover o Fusca, enfatiza sua simplicidade, que contrasta com a imponência e o luxo dos modelos que soem dominar o mercado norte-americano. A mesma agência é responsável pela campanha We try harder para a Avis, em 1962, na qual a empresa reconhece não ser líder no setor de locação de automóveis (posto ocupado pela Hertz), mas promete dedicar-se para fazer o máximo pelo consumidor. Em ambos os casos, a publicidade reconhece as limitações do produto anunciado, passando uma imagem inusual de franqueza, e ao mesmo tempo o aponta como alternativa para aqueles que não se preocupam em seguir a maioria.

As rupturas propostas pela revolução criativa da publicidade têm estreita relação com a contracultura, como mostra Frank (1997). A aparência inclusive dos profissionais da área modifica-se: se nos anos 1950 eles eram conhecidos pelos ternos de flanela cinza (indumentária celebrizada em The man in the gray flannel suit, best-seller de Sloan Wilson publicado em 1955 e adaptado para o cinema no ano seguinte, sob a direção de Nunnally Johnson e com Gregory Peck no papel principal), na década seguinte os tipos criativos passam a usar cabelos compridos e roupas coloridas. Por parte dos anunciantes de diversas áreas, há um esforço para demonstrar sintonia com o Zeitgeist. Numa campanha lançada em 1963, a Pepsi-Cola retrata seus consumidores como detentores de um estilo de vida jovem e ativo, ligado a esportes e aventuras: “Desperte! Você está na geração Pepsi!” Em 1965, a Dodge passa a propagandear seus modelos de automóvel com os slogans "Junte-se à rebelião Dodge" e "A rebelião Dodge quer você"; nos comerciais da campanha para a TV, uma loura estouvada protagoniza situações cômicas como donzela em perigo. Em 1968, a Columbia Records publica um anúncio em revistas como a Rolling Stone mostrando jovens presos numa cela, com visual rebelde e cartazes no chão, como se tivessem acabado de sair de uma manifestação. Ao lado, aparecem as capas de alguns discos de seu catálogo. O título é uma mensagem anti-establishment: "Mas O Homem não pode reprimir nossa música". 
A revolução criativa constitui um marco na história da publicidade, introduzindo uma nova estratégia retórica. Entre o publicitário e o consumidor é estabelecida uma relação de cumplicidade. O consumidor é tratado como alguém que tem seu próprio estilo e sabe o que quer. Simetricamente, o publicitário não se dirige a ele com uma postura de autoridade, mas coloca-se diante dele como um igual. Nos anúncios, é comum o recurso a um tom irreverente e o flerte com a transgressão. As mensagens por vezes são sutis, dando mais ênfase à marca ou a uma narrativa em torno do produto do que a este. A intenção é criar uma imagem cool do produto e fazer com que os consumidores queiram associar-se a ela.

Essa estratégia retórica torna-se prevalente nas últimas décadas. Um exemplo é o comercial de lançamento do computador Apple Macintosh, dirigido por Ridley Scott e apresentado nacionalmente nos Estados Unidos num dos intervalos do Super Bowl XVIII, em 1984. A referência é o romance 1984, de George Orwell. Num cenário futurista em tons azuis e cinzas, um homem encarnando o Big Brother discursa numa grande tela para uma plateia de pessoas robotizadas. Em contraste, a figura colorida de uma atleta, envergando uma camiseta que exibe o desenho estilizado do computador, corre perseguida por policiais. Quando o discurso se aproxima de seu desfecho, a jovem consegue chegar perto da tela e atira um grande martelo contra ela, fazendo-a explodir perante a plateia em choque. A mensagem final vincula explicitamente o produto com a ruptura da homogeneidade e do conformismo: "Em 24 de janeiro, a Apple Computer irá introduzir o Macintosh. E você verá por que 1984 não será como 1984".

A predominância da retórica da cumplicidade deve-se ao fato de que o consumo atualmente é um fator de individuação, não de adaptação. Não cabe impor um padrão, mas ajudar cada um a encontrar-se no mercado. Isso vale para os casos em que as opções de produtos são múltiplas e customizadas, mas, mesmo no caso de um modelo único, seu apelo é diferente para cada um.

Ainda que a retórica da cumplicidade trate o consumidor com mais respeito e recorra a mensagens mais sofisticadas, seu desígnio continua sendo o de fazer com que ele compre. Críticas como as de Packard (2007) e de Friedan (1963) a manipulações publicitárias são em princípio endossadas pelos profissionais da área, mas apropriadas e canalizadas para aperfeiçoar sua mensagem. A engrenagem em ação é típica da ideologia contemporânea e similar à da perversão (Castro, 2014): sabemos muito bem que o intuito do anúncio é nos induzir a consumir, mas fazemos de conta que ele consiste em mero entretenimento. Em certos casos, entretanto, até a consistência ideológica rateia. Algumas tentativas de adesão a mensagens transgressivas por parte de grandes 
corporações soam claramente artificiais, como no anúncio citado em que a Columbia Records posa, de forma desajeitada, como solidária aos jovens que protestam. Ademais, há uma discrepância entre a imagem glamorosa dos produtos e a realidade que cerca sua produção, como os baixos salários e as condições precárias de trabalho enfrentados por trabalhadores da Apple na Ásia.

\section{TECNOLOGIAS DE SI}

O discurso neoliberal caracteriza-se por eximir a sociedade de responsabilidade sobre os destinos individuais, transferindo esse encargo para cada um. Assim, se um trabalhador está desempregado, isso não é explicado como um problema estrutural do capitalismo ou sequer como um problema conjuntural gerado por políticas econômicas recessivas, mas como uma suposta deficiência pessoal de alguém que não se teria preparado devidamente para enfrentar circunstâncias vigentes no mercado de trabalho. Em consequência, a mobilização coletiva e reivindicatória dá lugar à iniciativa individual. "Os cidadãos de uma democracia liberal devem regular-se a si próprios; os mecanismos governamentais os interpretam como participantes ativos de suas vidas." (Rose, 1999: 10)

É natural, por conseguinte, que o neoliberalismo tenha profundas implicações em termos subjetivos. Essas implicações são buscadas de maneira deliberada: como declara Margaret Thatcher numa entrevista ao Sunday Times em 3 de maio de 1981, “a economia é o método, mas o objetivo é mudar a alma”. Em nossa época, dissemina-se uma visão individualista e terapêutica, similar à dos livros de autoajuda. O que importa para cada um é construir sua narrativa de triunfo, de realização de seu potencial e de superação de obstáculos, que são desconectados de sua dimensão social. Para tanto, recorre-se ao que Foucault (2001: 1602-1632), em suas análises da cultura antiga, havia denominado "técnicas de si".

No contexto neoliberal, o consumidor é considerado produtor de sua própria satisfação (Foucault, 2004: 232). O consumo integra-se à construção de identidade através de tecnologias de si, que se aliam para esse propósito à retórica da cumplicidade descrita anteriormente. É verdade que a cultura terapêutica não é uma novidade e que o consumidor no passado também investia em si. Tratavase, no entanto, da adequação a modelos predeterminados, enquanto na atualidade o consumidor elege seus modelos dentre múltiplas opções. Na sociedade de consumo contemporânea, a "reflexibilidade do eu é contínua, assim como onipresente" (Giddens, 1991: 76). Servindo-se de ferramentas que o consumo oferece, cada um pode redefinir sua identidade, por vezes com o auxílio de es- 
pecialistas, como ocorre em programas do tipo Extreme makeover, que oferecem a candidatos selecionados a transformação completa de sua aparência, acompanhada pari passu pelas câmaras de televisão. Ou seja, a identidade aparece como algo inteiramente modulável, dependendo somente dos recursos à disposição de cada um, como se a construção da identidade fosse um jogo de montar em que as peças são adquiridas no mercado. A publicidade incentiva o consumidor a engajar-se nesse jogo, seguindo seu próprio caminho e investindo em sua própria realização, por meio de conteúdos motivacionais acoplados a produtos.

Um exemplo é o slogan Just do it, da Nike, criado pela agência Wieden+Kennedy em 1988, normalmente utilizado junto do logo da empresa nos anúncios em vários tipos de mídia. Esses anúncios são estrelados por celebridades esportivas de várias modalidades, nacionalidades e etnias; com base no endosso dessas personalidades, a marca pretende associar-se a conotações de sucesso, esportividade e saúde. O slogan exorta o consumidor a abandonar sua vida sedentária. Ao mesmo tempo, a ideia é transformar o tênis num item prestigiado de moda, um calçado que pode ser usado por qualquer pessoa, e não exclusivamente por praticantes de esportes. O tom motivacional declina-se em mensagens no estilo de autoajuda, como no comercial Failure, de 1997, em que o ídolo do basquete Michael Jordan cita as numerosas vezes em que falhou em sua vitoriosa carreira (as cestas que perdeu, as partidas em que seu time foi derrotado, as chances de definir o jogo no final que desperdiçou) e conclui: "Foi por isso que fui bem-sucedido".

Também a campanha Think different, da Apple, elaborada pela agência TBWA Chiat\Day e lançada em 1997, alia uma mensagem motivacional ao investimento no prestígio do produto. Os anúncios destacam uma série de figuras históricas marcantes, como Albert Einstein, Bob Dylan, Martin Luther King, Jr., John Lennon, Thomas Edison, Muhammad Ali, Maria Callas, Mahatma Gandhi, Alfred Hitchcock, Pablo Picasso e outros. Após enfatizar seus aspectos controversos, o texto conclui: "Enquanto alguns podem vê-los como loucos, nós vemos o gênio. Porque as pessoas que são suficientemente loucas para pensar que elas são capazes de mudar o mundo são aquelas que o fazem". A ideia é reforçar a reputação de criatividade dos usuários da marca e usar esse apelo para atrair novos consumidores.

Apesar de apresentarem-se como ferramentas de responsabilização dos indivíduos por sua própria vida, as tecnologias de si estão apoiadas em modelos externos, ainda que múltiplos e flexíveis. Além disso, a construção da identidade pela via privilegiada do consumo envolve fatalmente um processo de reificação: se alguém é definido pelos objetos que consome, sua identidade tende a assumir o mesmo estatuto desses objetos. 


\section{MECANISMOS DE PARTICIPAÇÃO}

Para Hayek, referência fundamental do neoliberalismo, no mercado, tal como na atividade científica, há um processo colaborativo, no qual o resultado do concurso de várias pessoas é superior ao que poderia ser obtido individualmente:

A Razão humana, com R maiúsculo, não existe no singular, como dada ou disponível a qualquer pessoa em particular, como a abordagem racionalista parece assumir, mas deve ser concebida como um processo interpessoal no qual a contribuição de cada um é testada e corrigida por outros. (1948: 15)

Esse ideal parece realizar-se nas formas de interatividade trazidas pela internet, que tornam possível a disponibilização de dados sobre padrões de consumo e o contato direto dos compradores entre si, ou entre compradores e vendedores. São mecanismos relacionados, em tese, a um grau maior de participação do consumidor, se confrontados com modelos tradicionais de consumo. Tal participação acontece de maneira direta, quando o consumidor se engaja ativamente na provisão de informações e avaliações, ou indireta, quando ele deixa rastros digitais que se convertem em informações. Em todas essas formas de interatividade observa-se, aparentemente, um ganho de agência por parte do consumidor, na medida em que elas lhe facultariam tomar decisões melhor fundamentadas. Além do mais, cada consumidor influencia os outros de algum modo, pois contribui para determinar o que será oferecido a eles. O consumidor tem, portanto, algo de produtor, tendência já detectada por McLuhan, para quem "o consumidor torna-se produtor no circuito de automação, assim como o leitor da imprensa telegráfica em mosaico produz suas próprias notícias, ou simplesmente é suas próprias notícias" (1994: 349, grifo no original).

A coleta e o tratamento de dados sobre as atividades dos consumidores possibilitam o aperfeiçoamento das recomendações por eles recebidas. Numa livraria virtual, por exemplo, quando encomendamos um livro ou consultamos sua descrição, essa operação fica registrada em nosso perfil e a partir daí somos usualmente remetidos a outras obras que poderiam atrair nossa curiosidade. Isso pode ser feito com base nas similaridades mais evidentes extraídas da descrição das diversas obras - o fato de terem o mesmo autor ou versarem sobre o mesmo assunto. A mobilização da inteligência coletiva embutida nos dados, porém, propicia a identificação de conexões mais precisas, representadas pelas obras que costumam capturar a atenção dos que compartilham nosso interesse por determinado livro. Trata-se de uma espécie de informação que o vendedor não poderia obter ou fornecer ao consumidor de outro jeito, pois é produzida dinami- 
camente por meio da somatória das atividades da massa de consumidores. Isso vale especialmente para produtos, como livros, em que a gama de predileções de cada um é bastante pessoal. Complementarmente, a opinião de outros consumidores pode chegar a nós de forma individualizada, na medida em que os sites de comércio eletrônico incentivam seu input explícito, reservando espaços para que deixem comentários sobre os produtos à venda e atribuam-lhe notas.

Embora tenham uma variedade de outros usos, as redes sociais não raro servem igualmente para a troca de experiências entre consumidores e a discussão sobre as vantagens e desvantagens de produtos e marcas. Aqui, o vínculo entre o perfil do usuário e as sugestões que ele recebe em termos de consumo é, em certo sentido, mais difuso do que nas lojas online. Nestas, as atividades do consumidor consistem na compra - ou pelo menos na observação - dos itens à venda, ao passo que nas redes sociais o comércio não é geralmente algo central para o usuário. Mesmo assim, o apelo ao consumidor pode ser mais direto e abrangente. Desde seu início, o Facebook faz questão de destacar o slogan com a promessa de gratuidade do serviço (na versão em português: "É gratuito e sempre será"). A contrapartida é a utilização dos dados do usuário, que indicam seu perfil demográfico, suas preferências, suas atividades profissionais e de lazer, suas viagens, suas interações com outros etc., para direcionar-lhe recomendações. São informações bastante detalhadas, que podem ser associadas a uma vasta gama de produtos. $\mathrm{O}$ vínculo entre o consumidor e uma empresa torna-se ainda mais forte se ele curte sua página ou a de um de seus produtos, criando, a partir daí, uma conexão permanente. Isso permite que a empresa o abasteça regularmente com informações, além de utilizar sua aprovação para promover-se automaticamente junto a seus amigos. Há, ademais, os casos de viralização, em que o anúncio de uma empresa atrai o interesse dos usuários a ponto de o compartilharem, encarregando-se, na prática, de sua divulgação.

Nos agregadores de sites de comércio eletrônico, as comparações entre os vendedores assumem um caráter automatizado, viabilizando o cotejo de preços entre diversas lojas e mostrando onde é mais vantajoso comprar. Grandes lojas, como a Amazon, exibem atualmente não apenas suas próprias ofertas, mas também as de seus parceiros comerciais para os mesmos produtos, reproduzindo em seu interior os dispositivos de comparação de preços.

Sites como eBay e Mercado Livre, que surgiram como mecanismos de leilão virtual, com ênfase em produtos usados, passaram a funcionar como canais de comércio em geral, reunindo vendedores e compradores pulverizados. Eles abrem acesso a produtos que dificilmente seriam comercializados de outra forma no mercado, bem como a seus respectivos vendedores; colocam 
vendedores e compradores em contato direto, eliminando etapas desnecessárias de intermediação; e ensejam a comparação de preços, quando efetuamos uma busca por dado produto e nos deparamos com vários resultados.

As vantagens trazidas pelo mundo virtual no que tange ao consumo representam uma mudança de escala em relação ao que sucede no mundo físico. Se compararmos o número e a natureza da clientela em diferentes estabelecimentos numa rua ou shopping center, isso de alguma maneira influencia nossa opinião sobre eles. Um comentário boca a boca ou a simples visão de outra pessoa usando um produto pode provocar em nós uma disposição mais ou menos favorável a respeito dele. Pesquisas de preços podem ser feitas percorrendo várias lojas. A redução da intermediação entre vendedor e comprador ocorre no chamado marketing de rede. Fãs offline vestem roupas com alusão a dado produto ou organizam encontros em torno dele. Grosso modo, a facilidade de acesso às ofertas online amplia as oportunidades de aquisição de bens para além das barreiras geográficas e dos canais convencionais de comercialização, entronizando o consumidor contemporâneo numa posição em princípio privilegiada em relação a seus antecessores. Não cabe estranhar, consequentemente, que o discurso neoliberal teça loas à economia virtual. Nesse contexto se enquadra a expressão "capitalismo sem friç̧ão", empregada por Bill Gates (1996), da Microsoft, para designar esse mercado em que tudo parece funcionar harmoniosamente, sem as perturbações trazidas por distância, regulações, custos e deficiências de informação. A tudo isso se agrega outro fator, apontado por Bauman (2007: 18): quando entro numa loja física, coloco-me à mercê dos poderes de persuasão do vendedor e de minha própria fraqueza em comprar por impulso, enquanto na internet "sou o único que permanece no comando e segura o volante", podendo em tese ponderar melhor o que me traz vantagens.

A facilidade oferecida pela internet, todavia, sem contar os apelos específicos do comércio online, como as promoções do tipo Black Friday ou Cyber Monday, pode na verdade induzir ao consumismo, ou até à oniomania, o vício em compras. Na medida em que a estrutura de Big Data está nas mãos de grandes corporações, não temos controle sobre os dados que estão sendo coletados, como eles estão sendo analisados e como isso afeta o que nos está sendo oferecido. Um risco envolvido no uso de dados para predizer gostos e interesses do consumidor é o de encerrá-lo numa bolha digital, oferecendo-lhe conteúdo sempre do mesmo gênero. Outro problema é a distorção das recomendações - quando uma parte interessada paga para figurar com destaque nos resultados de uma busca, por exemplo. Além disso, a classificação do consumidor com base em seus dados pode funcionar como um instrumen- 
to de discriminação, quando, por exemplo, esses dados são utilizados para fundamentar decisões sobre ofertas, descontos, crédito etc. Cumpre também levar em conta as diferenças entre os usuários quanto às condições de acesso à internet e ao domínio das ferramentas online.

Como as corporações se valem do controle sobre os dados para seu próprio ganho, o consumidor é de certo modo recrutado para trabalhar para elas. Se desejo aumentar a precisão da lista de recomendações que recebo numa livraria virtual, cabe a mim editar essa lista, informando o grau de atratividade de cada novo item aconselhado para mim e se já não o possuo; no limite, acabarei fornecendo todo o conteúdo de minha biblioteca e todas as aquisições que tenho em vista. Se posto numa rede social um relato detalhado de tudo que faço e de todos os meus gostos, estou ajudando, ainda que involuntariamente, a construir meu perfil como consumidor, a refinar as sugestões a mim direcionadas e a avalizar as sugestões feitas a outros. A Declaração de direitos e responsabilidades do usuário do Facebook, com data de revisão de 15 de novembro de 2013, é explícita a esse respeito:

Você nos concede permissão para usar seu nome, a imagem do perfil, conteúdo e informações em relação a conteúdo comercial, patrocinado ou relacionado (como uma marca que você gosta) fornecido ou aperfeiçoado por nós. Isto significa que, por exemplo, você permite uma empresa ou outra entidade a nos pagar para exibir seu nome e/ou imagem do perfil com seu conteúdo ou informações, sem qualquer compensação a você.

E, se alguém se coloca deliberadamente na posição de fã de uma empresa ou de seus produtos, sua subordinação aos interesses da empresa torna-se mais explícita - com a vantagem adicional, para a empresa, de que, em comparação com os fãs offline, os online são muito mais fáceis de rastrear e alistar.

Quando recebemos dicas de consumo via Big Data, a contribuição de cada um nessa acumulação de dados esfumaça-se. Permanece, contudo, o fato de que se trata de uma influência que vem de fora. Essa determinação externa, mais sutil que a das sociedades disciplinares, aproxima-se do que Deleuze (2003) denomina "sociedade de controle". A multiplicação de dados para guiar-nos em cada decisão, ademais, indica uma complexificação ao extremo das escolhas em cada detalhe da vida, um recurso intensivo ao cálculo que vai na contramão de valores como acaso, espontaneidade e intuição. 


\section{RESPONSABILIDADE SOCIAL}

Ao longo do século XX tem sido notado que, por intermédio de suas escolhas, o consumidor influencia diretamente os destinos da sociedade. O consumo aparece inclusive como modelo e sucedâneo do regime representativo:

As massas da América elegeram Henry Ford. Elas elegeram a General Motors. Elas elegeram a General Electric Company, e a Woolworth's, e todos os outros grandes líderes industriais e de negócios de hoje. [...] Elas não votam com cédulas, mas com dólares. (Filene, 1932: 135).

Hutt (1936: 257) cunha a expressão "soberania do consumidor" e declara: "O consumidor é soberano quando, em seu papel de cidadão, ele não delegou às instituições políticas, para uso autoritário, o poder que ele pode exercer socialmente através de seu poder de demandar (ou evitar demandar)".

No neoliberalismo, o alcance social e político das escolhas feitas pelo consumidor é enfatizado. A responsabilidade do indivíduo não se exerce somente na administração de sua vida, mas estende-se também a questões de natureza coletiva. Nesses casos, o enfraquecimento do engajamento social torna-se evidente: o consumidor é investido da tarefa de corrigir distorções que afetam o funcionamento da sociedade capitalista por meio da mera mudança em seus hábitos, agindo, portanto, de forma estritamente individual. Insere-se aí a fórmula do chamado consumo responsável.

O consumo ambientalmente consciente, por exemplo, deposita nas costas do consumidor a responsabilidade de reverter o enorme passivo ecológico do capitalismo, que representa hoje uma ameaça para todos, via decisões informadas de consumo. A lógica utilizada é a de que cada um pode fazer diferença graças a suas escolhas. Se cada um se encarregasse de reciclar seu lixo, ficasse atento ao impacto ambiental dos produtos que consome, selecionasse as empresas das quais é cliente conforme sua reputação em matéria de sustentabilidade, se preocupasse com sua pegada ecológica (ou seja, a medida em que seu estilo de vida, se generalizado a toda a humanidade, sobrecarrega ou não o planeta), a soma dessas ações atomizadas teria o condão de minimizar um problema de alcance coletivo. Assim, temos aqui um desdobramento no plano social e político das tecnologias de si no plano individual.

A ideia de consumo responsável coaduna-se muito bem com a retórica de cumplicidade descrita anteriormente, segundo a qual anunciantes (e as corporações por eles representadas) e consumidores estão do mesmo lado, têm o mesmo objetivo, não apresentam divergências e conflitos de interesses. Através dela, as empresas terceirizam sua responsabilidade para o consumidor. Sempre 
que possível, as decisões são transferidas para este: é ele quem deve optar, por exemplo, de acordo com sua consciência, por usar uma sacola de papel em lugar de uma sacola de plástico. Isso aparece como um instrumento de satisfação e realização para o próprio consumidor, permitindo que ele continue a consumir em paz com sua consciência. Pesquisas de opinião mostram que a sustentabilidade é um valor importante para uma considerável parcela do público, atraindo particularmente aqueles com maior nível de instrução. Na medida em que esse valor constitui um fator de status, cria-se um incentivo para a chamada conservação conspícua, variante contemporânea do conceito vebleniano de consumo conspícuo. Tanto as empresas que exaltam o consumo responsável como os consumidores que adotam esse comportamento acumulam o que se poderia chamar de capital ético, variante do capital humano celebrado pelo neoliberalismo.

O resultado é curioso, pois o consumo passa a ser encarado, na prática, não como fonte de pressões sobre o ambiente, mas como a própria solução. Diante de problemas causados pelo consumo, a saída é continuar a consumir. Para salvar o planeta, basta que esse consumo seja correto. Assim como o café sem cafeína, a cerveja não alcoólica e outros produtos esvaziados de suas propriedades, mencionados por Žižek (1992: 65), o consumo aqui é tomado por seu oposto, como se fosse anticonsumo. Isso lembra igualmente os slogans do tipo "leve 3 e pague 2", que sugerem paradoxalmente comprar mais como meio de poupar. É esse justamente o raciocínio por trás do conceito lacaniano de mais-de-gozar (plus-de-jouir), uma espécie de gozo excedente que resulta da repressão ao gozo. E o que se verifica aqui não é uma analogia casual, uma mera similaridade de estrutura, pois na verdade o consumo contemporâneo tem estreita vinculação com o gozo.

Em 2009, a Coca-Cola da Grã-Bretanha lança a campanha "Keep it going. Recycle." A mensagem para o consumidor é a de satisfazer-se com a bebida e em seguida dispor adequadamente de sua embalagem: "Enjoy a coke. Recycle the bottle". Com isso, combinam-se o gozo e a consciência ambiental, apresentados como perfeitamente compatíveis. O próprio símbolo da reciclagem incorpora em seu interior uma imagem estilizada da garrafa do refrigerante. Afora os anúncios, a iniciativa desdobra-se na construção de contêineres em pontos fixos e em eventos para coletar o material a ser reciclado, dando visibilidade à campanha. Repercussão e prestígio para a marca são obtidos também por meio da instalação intitulada Precious metal, montada no mesmo ano em Sussex. Contendo 200 mil latas recolhidas em todo o país, a gigantesca instalação, a cargo do artista Robert Bradford e de uma equipe de voluntários, consiste na reprodução de um pôster da Coca-Cola de 1949, visível a partir 
de fotografias aéreas; após sua desmontagem, todas as latas são enviadas para reciclagem.

A terceirização de responsabilidades para o consumidor pode trazer às corporações oportunidades complementares de ganho. Para estimular seus clientes a abrirem mão do recebimento de extratos e faturas de papel pelo correio, optando por consultarem versões desses documentos pela internet, o Itaú recorre em 2012 a um vídeo que se tornara viral no YouTube. Nele, o bebê Micah ri histericamente ao observar seu pai rasgando pedaços de papel na frente dele. Após acordo com a família, moradora da Califórnia, as imagens são transformadas num comercial de televisão. Um segundo filme, apresentando os pais do bebê, dá sequência à campanha, que é bastante efetiva no sentido de incentivar a mudança de hábitos dos clientes. Trata-se de uma mudança interessante para o banco, pois implica uma redução de custos. Quando, no mesmo ano, vigora durante alguns meses a proibição do uso de sacolas de plástico pelos supermercados na cidade de São Paulo, os maiores favorecidos são os próprios estabelecimentos, que veem seus custos com embalagem serem reduzidos drasticamente e beneficiam-se adicionalmente com a venda de sacolas recicláveis. No caso da reciclagem, o consumidor em geral trabalha gratuitamente para todo um ramo de atividade que lucra com isso, selecionando e fornecendo sua matéria-prima. Outra modalidade de ganho com o consumo responsável é ilustrado pela rede de cafés Starbucks, que cobra mais caro por seus produtos graças à associação da marca com compromissos em matéria de sustentabilidade, fair trade etc. (embora a empresa também seja conhecida nos Estados Unidos por atitudes antissindicais).

Além de lucrar com o consumo responsável, as corporações valem-se dele, por vezes, para mascarar suas responsabilidades. Quando um hotel sugere aos hóspedes a reutilização de lençóis e toalhas, omite que ele poderia adotar muitas outras práticas sustentáveis. Esse exemplo, aliás, leva o ativista nova-iorquino Jay Westerveld a cunhar, num ensaio escrito em 1986, o termo "greenwashing", mais tarde dicionarizado. Ele designa posturas supostamente em defesa do meio ambiente que são pouco efetivas - valendo-se de nomes sugestivos, enfatizando atributos vagos ou pouco relevantes, recorrendo a alegações ou endossos não substanciados, fazendo comparações indevidas - e visam apenas transmitir uma aparência de sustentabilidade para satisfazer as demandas dos consumidores ou de órgãos governamentais. Às vezes os custos dessas providências, além de irrelevantes em comparação com os lucros das empresas, são inferiores inclusive aos gastos de marketing para anunciá-las, sendo contrabalançados ademais pelos ganhos em termos de imagem. Em sua campanha Better world, em 2011, a Nike leva o greenwashing à práxis 
publicitária, fazendo um comercial reciclado, isto é, composto inteiramente de imagens provenientes de antigos comerciais; o que importa aqui, obviamente, é o conceito, não o eventual benefício ao meio ambiente.

Seguindo a trilha de Marx, Berman comenta, a propósito das contradições do capitalismo:

Esse sistema exige constante revolução, perturbação, agitação; ele precisa ser perpetuamente empurrado e pressionado para manter sua elasticidade e resiliência, para apropriar-se de e assimilar novas energias, para dirigir-se a um novo patamar de atividade e crescimento. Isso significa, no entanto, que homens e movimentos que proclamam sua inimizade com o capitalismo podem ser exatamente o tipo de estimulante de que o capitalismo precisa. (1988: 118)

Há vários episódios históricos em que uma agenda teoricamente progressista é apropriada pelo capital pela via do consumo. No início do século XX, nos Estados Unidos, o progressivismo começa atacando as corporações e termina apontando-lhes o caminho para controlar o consumidor - a trajetória de Walter Lippmann é bastante reveladora nesse aspecto. Nos anos 1930, como mostra Ewen (1996: 322-336), a retórica do New Deal é adaptada pelo mundo dos negócios, transformando-se numa celebração do consumidor segundo a ideologia da livre empresa, num tour de force de relações públicas que culmina na Feira Mundial de 1939, em Nova York. A incorporação do discurso da sustentabilidade por parte das corporações, na forma de estímulo ao consumo responsável, assim como a incorporação do discurso da contracultura pela publicidade, insere-se nessa linha. Na medida em que substitui a mobilização, o consumo responsável representa a colonização do ativismo pelo mercado, equivalendo a uma reificação da consciência política. $\mathbf{M}$

\section{REFERÊNCIAS}

BAUMAN, Z. Consuming life. Cambridge/Malden: Polity, 2007.

BERMAN, M. All that is solid melts into air: the experience of modernity. Nova York: Penguin, 1988.

BOLTANSKI, L.; CHIAPELLO, È. Le nouvel esprit du capitalisme. Paris: Gallimard, 1999.

CASTRO, J. C. L. A publicidade contemporânea e o paradigma da perversão. Comunicação, Mídia e Consumo, São Paulo, v. 11, n. 30, p. 181-198, jan./abr. 2014.

DE CERTEAU, M. Linvention du quotidien, tome 1: arts de faire. Paris: Gallimard, 1990. 
DELEUZE, G. Post-scriptum sur les sociétés de contrôle. In: Pourparlers: 1972-1990. Paris: Minuit, 2003. p. 240-247.

EWEN, S. PR! A social history of spin. Nova York: Basic Books, 1996.

FILENE, E. A. Successful living in this machine age (in collaboration with Charles W. Wood). Londres/Toronto: Jonathan Cape, 1932.

FOUCAULT, M. Dits et écrits, II: 1976-1988. Paris: Gallimard, 2001. Naissance de la biopolitique: cours au Collège de France, 1978-1979. Paris: Gallimard/Seuil, 2004.

FRANK, T. C. The conquest of cool: business culture, counterculture, and the rise of hip consumerism. Chicago/Londres: University of Chicago Press, 1997.

FRIEDAN, B. The feminine mystique. Nova York: W. W. Norton, 1963.

GATES, B. The road ahead. Nova York/Londres: Penguin, 1996.

GIDDENS, A. Modernity and self-identity: self and society in the late modern age. Cambridge: Polity, 1991.

HAYEK, F. A. Individualism and economic order. Chicago: University of Chicago Press, 1948.

HUTT, W. H. Economists and the public. Londres: Jonathan Cape, 1936.

LEÃO, N. Coisas do mundo. Philips, 1969.

MAILER, N. The white Negro: superficial reflections on the hipster. Dissent, v. 4, n. 3, p. 276-293, Summer 1957.

McGREGOR, D. The human side of enterprise. Nova York: McGraw-Hill, 1960.

McLUHAN, M. Understanding media: the extensions of man. Cambridge/Londres: MIT Press, 1994.

MILLER, D. Material culture and mass consumption. Oxford: Basil Blackwell, 1987.

PACKARD, V. The hidden persuaders. Nova York: Ig, 2007.

RIESMAN, D. The lonely crowd: a study of the changing American character. New Haven/Londres: Yale University Press, 2001.

ROSE, N. Governing the soul: the shaping of the private self. 2nd ed. Londres/ Nova York: Free Association Books, 1999.

SMITH, A. An inquiry into the nature and causes of the wealth of nations, vol. 2. Indianapolis: LibertyClassics, 1981.

ŽIŽEK, S. Enjoy your symptom! Jacques Lacan in Hollywood and out. Nova York/Londres: Routledge, 1992.

Artigo recebido em 23 de outubro de 2014 e aprovado em 28 de abril de 2015 . 